\title{
Impact of UGT2B7 His268Tyr polymorphism on the outcome of adjuvant epirubicin treatment in breast cancer
}

\author{
Sumit Parmar ${ }^{1}$, Julia Carolin Stingl ${ }^{1}$, Ariana Huber-Wechselberger ${ }^{2}$, Alexander Kainz ${ }^{3}$, Wilfried Renner ${ }^{4}$, \\ Uwe Langsenlehner $^{5}$, Peter Krippl ${ }^{5}$, Jürgen Brockmöller ${ }^{6}$ and Elisabeth Haschke-Becher ${ }^{2,7^{*}}$
}

\begin{abstract}
Introduction: Epirubicin is a common adjuvant treatment for breast cancer. It is mainly eliminated after glucuronidation through uridine diphosphate-glucuronosyltransferase 2B7 (UGT2B7). The present study aimed to describe the impact of the UGT2B $7^{\text {His } 2687 y r}$ polymorphism on invasive disease-free survival in breast cancer patients after epirubicin treatment.

Methods: This is a pharmacogenetic study based on samples collected from 745 breast cancer patients of the Austrian Tumor of breast tissue: Incidence, Genetics, and Environmental Risk factors (TIGER) cohort who did not present metastases at baseline. This cohort included 205 women with epirubicin-based combination chemotherapy, 113 patients having received chemotherapy without epirubicin and 427 patients having received no chemotherapy at all. Of the epirubicin-treated subgroup, 120 were subsequently treated with tamoxifen. For all women UGT2B $7^{\text {His268Tyr }}$ was genotyped. Invasive disease-free survival was assessed using Kaplan-Meier and Cox's proportional hazard regression analysis.
\end{abstract}

Results: Among the 205 epirubicin-treated patients, carriers of two UGT2B7 $7^{268 T y r}$ alleles had a mean invasive disease-free survival of 8.6 (95\% confidence interval (Cl) 7.9 to 9.3) years as compared to 7.5 (95\% Cl 6.9 to 8.0 ) years in carriers of at least one UGT2B $7^{268 H i s}$ allele (adjusted hazard ratio (HR) $=2.64(95 \% \mathrm{Cl} 1.22$ to 5.71 ); $P=$ 0.014). In addition, the impact of the UGT2B $7^{\text {His268Tyr }}$ polymorphism became even more pronounced in patients subsequently treated with tamoxifen (adjusted HR $=5.22(95 \% \mathrm{Cl} 1.67$ to 26.04); $P=0.015$ ) whereas no such difference in invasive disease-free survival was observed in patients not receiving epirubicin.

Conclusions: Breast cancer patients carrying the UGT2B ${ }^{268 T y r / T y r}$ genotype may benefit most from adjuvant epirubicin-based chemotherapy. These results warrant confirmation in further studies.

\section{Introduction}

Anthracyclines are commonly used for neoadjuvant or adjuvant chemotherapy of locally advanced breast cancer $[1,2]$. They act by inhibition of topoisomerase II alpha and generation of reactive oxygen species eventually resulting in cell cycle arrest and apoptosis [3,4]. Epirubicin is a semisynthetic derivative of doxorubicin preferentially used in breast cancer treatment. It is extensively metabolized in the liver to epirubicinol by aldo-keto

\footnotetext{
* Correspondence: elisabeth.haschke@elisabethinen.or.at

${ }^{2}$ Institute of Medical and Laboratory Diagnostics, Elisabethinen Hospital Linz, Fadingerstrasse 1, Linz, 4020, Austria

Full list of author information is available at the end of the article
}

reductase and in addition aglycones of epirubicin and epirubicinol are formed [5]. The major inactivation pathway for epirubicin and epirubicinol is glucuronidation catalysed by UDP-glucuronosyltransferases (UGT). Studies using human liver microsomes, expressing UGT1A1, UGT1A3, UGT1A4, UGT1A6, UGT1A9, UGT2B7 and UGT2B15 revealed that UGT2B7 uniquely converts epirubicin to its glucuronide [6]. In addition, also the active metabolites of tamoxifen are eliminated by UGT2B7 mediated glucuronidation [7].

The $U G T 2 B 7$ gene is polymorphic with a frequent non-synonymous variant $802 \mathrm{C}>\mathrm{T}$ leading to a histidine to tyrosine substitution in codon 268 (His268Tyr).
C Biomed Central

() 2011 Parmar et al.; licensee BioMed Central Ltd. This is an open access article distributed under the terms of the Creative Commons Attribution License (http://creativecommons.org/licenses/by/2.0), which permits unrestricted use, distribution, and reproduction in any medium, provided the original work is properly cited. 
The functional impact of this polymorphism is unclear as studies have shown lower [8-12], similar [13-15], and even higher enzyme activity of the UGT2B7 ${ }^{268 \mathrm{Tyr}}$ isoform [16-18]. Two in vitro studies showed no impact of the UGT2B $7^{\text {His } 268 T y r}$ genotype on the epirubicin glucuronide formation $[6,19]$. However, the presently available in vitro studies cannot finally clarify, if variants linked with the UGT2B $7^{\text {His } 268 T y r}$ polymorphism may modulate up- or downregulation of the enzyme under the conditions of adjuvant or neoadjuvant chemotherapy and in vitro models can, of course, never fully resemble the in vivo conditions [19-22]. UGT2B7 haplotype analysis revealed six promoter variants $(-1306 \mathrm{G}>\mathrm{A},-1299 \mathrm{C}>$ $\mathrm{T},-1112 \mathrm{C}>\mathrm{T},-900 \mathrm{~A}>\mathrm{G},-327 \mathrm{G}>\mathrm{A}$ and $-161 \mathrm{C}>\mathrm{T}$ ) which modulate UGT2B7 promoter activity and are in perfect linkage disequilibrium with the UGT2B $7^{\text {His } 268 T y r}$ variant $[19,20,22,23]$. In contrast, for 4-hydroxy-tamoxifen and endoxifen, the active metabolites of tamoxifen, a decreased glucuronidation activity was shown for the UGT2B7 ${ }^{268 \text { Tyr }}$ isoform in vitro [9].

Here we present a pharmacogenetic (PGt) analysis of the Austrian Tumor of breast tissue: Incidence, Genetics, and Environmental Risk factors (TIGER) study $[24,25]$ to explore the effect of the UGT2B $7^{\text {His } 268 T y r}$ polymorphism on invasive disease-free survival after epirubicin treatment.

\section{Materials and methods}

\section{Study design}

The TIGER study was a cohort study to investigate genetic and environmental risk factors relevant to the onset and course of breast cancer [24,25]. As described earlier [26], the complete cohort consisted of 804 consecutive women with histologically confirmed breast cancer and no other cancer diagnosis, treated at the Division of Oncology, Department of Internal Medicine, Medical University Graz, Austria between January 2000 and September 2004. For the purpose of this PGt study, patients presenting with metastases already at baseline (stage IV) or not having biomaterial available for PGt analyses were excluded. At stage IV host genetic polymorphisms were considered much less relevant for survival and sample size in this subgroup was too small $(n=38)$ to allow adjustment or stratified analysis for this stage of disease. Patients were regularly followed-up with clinical examinations, laboratory (including CEA and CA15-3), radiological (bone scan, liver scan, chest X-ray, and mammograms), and gynecological analyses at three-year intervals until 2010 [24].

The study complied with the Declaration of Helsinki and was performed according to the Austrian Gene Technology Act. The protocol has been approved by the Ethical Committee of the Medical University Graz.
Written informed consent was obtained from all participating subjects.

\section{UGT2B7 genotyping}

DNA was isolated from venous blood (Qiamp DNA Mini-Kit, Qiagen, Hilden, Germany). Genotyping for UGT2B7 $802 C>T$ was performed blinded to the clinical outcomes using the validated TaqMan ${ }^{\circledR}$ SNP Genotyping Assay (C__32449742_20, Applied Biosystems, Foster City, CA, USA). Real-time PCR reactions were set up in a final volume of $12.5 \mu$ l containing TaqMan ${ }^{\circledR}$ Genotyping Master Mix, $20 \times$ SNP Genotyping Assay (Applied Biosystems, Foster City, CA, USA) distilled water and 3 to $20 \mathrm{ng}$ genomic DNA. PCR amplification was carried out using the Real Time PCR System 7300 (Applied Biosystems) under the following conditions: 10 minutes $95^{\circ} \mathrm{C}$ enzyme activation followed by 40 cycles at $92^{\circ} \mathrm{C}$ for $15 \mathrm{~s}$ and at $60^{\circ} \mathrm{C}$ for 1 minute.

\section{Statistical analysis}

Invasive disease-free survival was defined as the time from diagnosis to any local, regional, or distant recurrence, metastases or contralateral breast cancer or death from any cause, but excluded second primary invasive cancer to consider only events which may reflect efficacy of initial epirubicin drug treatment [27]. KaplanMeier estimates were calculated and the log-rank test was used to compare invasive disease-free survival of different UGT2B $7^{\text {His268Tyr }}$ variant carriers after (1) adjuvant chemotherapy with epirubicin, (2) adjuvant chemotherapy with epirubicin and tamoxifen, (3) adjuvant chemotherapy other than epirubicin, or (4) no adjuvant chemotherapy at all. In the latter two subgroups no difference was expected and thus served as controls. Cox's proportional hazard modeling was used for subsequent multivariate analyses with adjustments for clinical prognostic factors such as tumor size, age at diagnosis, nodal status, and histological grade. Proportional hazards were assessed by Schoenfeld residuals as well as by including the interaction terms of covariates with time into the model. Possible differences in patient characteristics between the respective treatment and genotype groups were assessed using Chi-square test, Kruskal-Wallis test or Mann-Whitney test. All tests were two-sided, performed at a significance level of 0.05 using SPSS 17.0 (SPSS Inc., Sunnyvale, CA, USA).

\section{Results}

\section{Study population}

Of the original 804 patients of the TIGER cohort, 59 patients were excluded from this analysis due to metastases already at baseline, the lack of material for PGt analyses, or the revision of the breast cancer diagnosis during follow-up (Figure 1). Of the remaining 


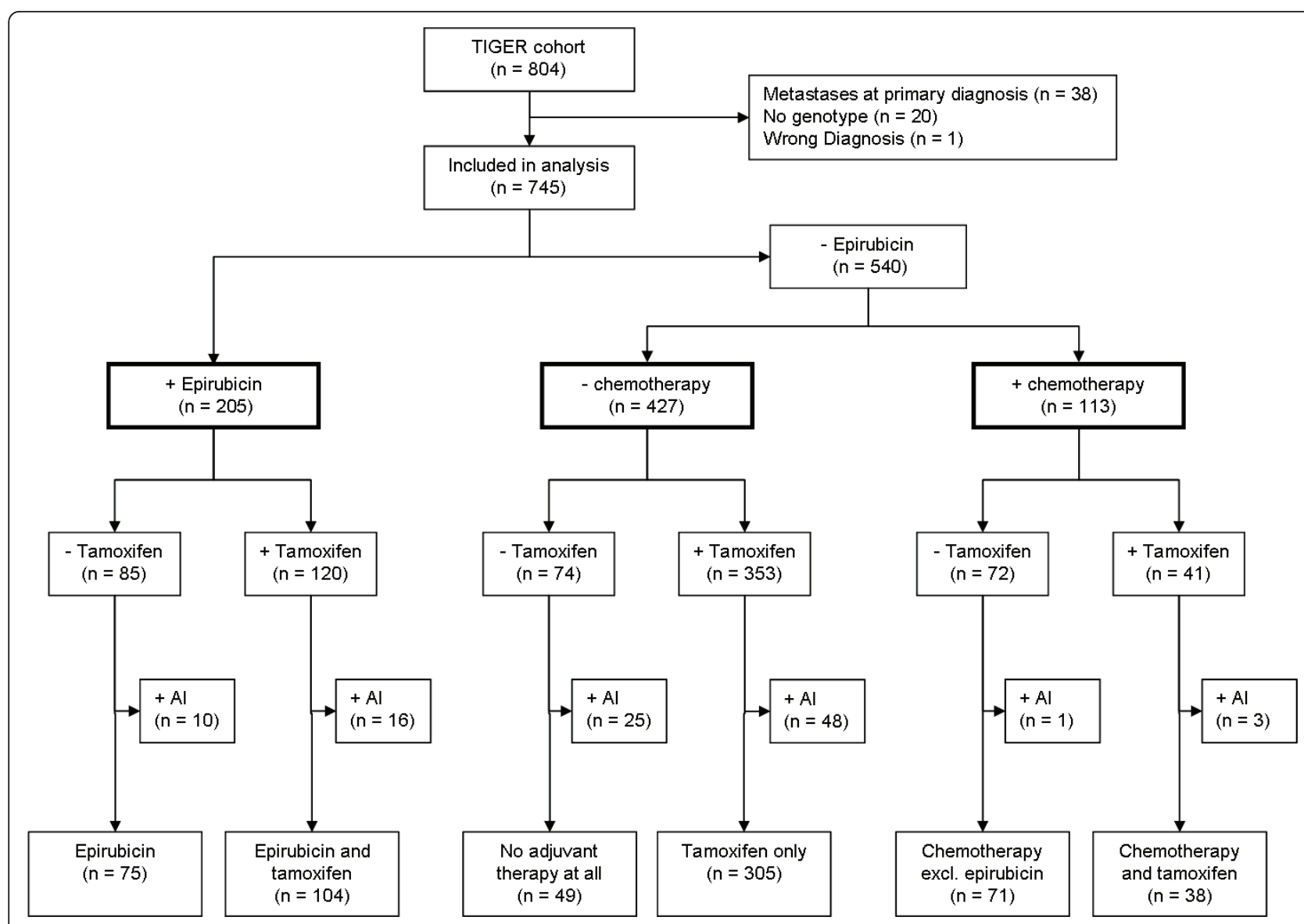

Figure 1 Patient flow chart based on the original TIGER cohort. Al, aromatase inhibitor, TIGER, Austrian tumor of breast tissue: incidence, genetics, and environmental risk factors study.

745 patients, 205 received epirubicin-based combination chemotherapy, 113 combination chemotherapy without epirubicin (mostly cyclophosphamide, methotrexate and fluorouracil), and 427 no adjuvant chemotherapy at all. Of the 205 epirubicin-treated patients, 120 subsequently also received tamoxifen (Figure 1).

\section{Invasive disease-free survival by treatment}

Patients who underwent adjuvant chemotherapy significantly differed from the remaining patients in clinical prognostic factors such as age, tumor size, grade, and nodal status (Table 1). Mean invasive disease-free survival times differed accordingly, with 7.9 years (95\% confidence interval (CI) 7.4 to 8.3 ) in epirubicin-treated patients, 6.9 years (95\% CI 6.1 to 7.6$)$ in patients with adjuvant therapy other than epirubicin, and 9.1 years ( $95 \%$ CI 8.8 to 9.4 ) in the remaining patients. Corresponding rates of patients with disease progression during a mean follow-up period of $6.6 \pm 2.0$ years were $27.8 \%, 46.9 \%$, and $18.3 \%$, respectively.

\section{Invasive disease-free survival by UGT2B7 His268Tyr genotype}

In the entire cohort, 147 (19.7\%) patients carried two histidine alleles, 352 (47.2\%) were heterozygous and 246 (33.0\%) carried two tyrosine-alleles. UGT2B ${ }^{268 T y r}$ allele frequency was $57 \%$ and genotype frequencies matched Hardy Weinberg equilibrium (Chi square test, $P=0.27$ ). Neither did frequencies of genotypes vary significantly among the three different treatment groups (Chi-square, $P=0.93$ ) nor did epirubicin-treated carriers of different variants differ in tumor size, grade, and nodal status at baseline (Table 2). However, carriers of at least one $U G T 2 B 7^{268 H i s}$ allele were slightly older than non-carriers at baseline $(54.4 \pm 10.2$ versus $50.1 \pm 10.7$; MannWhitney test, $P=0.01$ ).

In epirubicin-treated patients an association between the UGT2B $7^{\text {His } 268 T y r}$ polymorphism and invasive disease-free survival was observed (log-rank $P=0.05)$. By comparing carriers and non-carriers of the $U G T 2 B 7^{268-}$ His allele a significantly increased relapse risk was observed for the carriers of the UGT2B $7^{268 H i s}$ allele 
Table 1 Baseline characteristics by treatment

\begin{tabular}{|c|c|c|c|c|}
\hline Adjuvant chemotherapy & Epirubicin & No epirubicin & None & $P^{*}$ \\
\hline Total patients No. (\%) & $205(27.5 \%)$ & $113(15.2 \%)$ & 427 (57.3\%) & \\
\hline Age in years (mean, SD) & $53.0(10.5)$ & $55.6(12.6)$ & $60.5(12.0)$ & $<0.001$ \\
\hline Tumor size & & & & $<0.001$ \\
\hline$\leq \mathrm{T} 1(\leq 20 \mathrm{~mm})$ & 75 (36.6\%) & $59(52.2 \%)$ & $296(69.3 \%)$ & \\
\hline$\geq \mathrm{T} 2$ & $127(62.0 \%)$ & $50(44.2 \%)$ & $121(28.3 \%)$ & \\
\hline unknown & $3(1.5 \%)$ & $4(3.5 \%)$ & $10(2.3 \%)$ & \\
\hline Lymph nodes & & & & $<0.001$ \\
\hline 0 & $32(15.6 \%)$ & $45(39.8 \%)$ & $262(61.4 \%)$ & \\
\hline$\geq 1$ & $162(79.0 \%)$ & $57(50.4 \%)$ & $131(30.7 \%)$ & \\
\hline unknown & $11(5.4 \%)$ & $11(9.7 \%)$ & $34(8.0 \%)$ & \\
\hline Grade & & & & $<0.001$ \\
\hline 1 & $3(1.5 \%)$ & $4(3.5 \%)$ & 45 (10.5\%) & \\
\hline 2 & $63(30.7 \%)$ & $31(27.4 \%)$ & $260(60.9 \%)$ & \\
\hline$>2$ & $128(62.4 \%)$ & 77 (68.1\%) & $107(25.1 \%)$ & \\
\hline Unknown & 11 (5.4\%) & 1 (0.9\%) & 15 (3.5\%) & \\
\hline
\end{tabular}

* P-values are indicated for the comparison of patients treated with adjuvant chemotherapy (with or without epirubicin) vs. patients not treated with any adjuvant chemotherapy.

$\mathrm{SD}$, standard deviation

(Figure 2a; log-rank $P=0.017)$. The incidences of relapses and other events constituting a disease progression were $33.1 \%$ and $15.2 \%$ in carriers and non-carriers of the $U G T 2 B 7^{268 H i s}$ allele, respectively. Accordingly, carriers of at least one $U G T 2 B 7^{268 H i s}$ allele had a shorter mean invasive disease-free survival time of 7.5 years (95\% CI 6.9 to 8.0 ) as compared to 8.6 years $(95 \%$ CI 7.9 to 9.3 ) in $U G T 2 B 7^{268 T y r / T y r}$ carriers (Figure 2a, Table 3 ). The unadjusted hazard ratio (HR) for carriers of at least one $U G T 2 B 7^{268 H i s}$ allele was 2.24 (95\% CI 1.13 to 4.44; $P=0.021$ ). Cox's regression models with adjustment for age at diagnosis, nodal status and tumor grade,

Table 2 Characteristics of epirubicin-treated patients by UGT2B ${ }^{\text {His268Tyr }}$ genotype

\begin{tabular}{lccc}
\hline UGT2B7 ${ }^{\mathbf{2 6 8}}$ Genotype & Tyr/Tyr & His/Tyr + His/His & $P$ \\
\hline Number (\%) & $66(32.2 \%)$ & $139(67.8 \%)$ & \\
Age in years (mean, SD) & $50.1(10.7)$ & $54.4(10.2)$ & 0.01 \\
Tumor size & & & 0.12 \\
$\quad \leq \mathrm{T1}(\leq 20 \mathrm{~mm})$ & $29(43.9 \%)$ & $46(33.1 \%)$ & \\
$\geq \mathrm{T} 2$ & $35(53.0 \%)$ & $92(66.2 \%)$ & \\
$\quad$ unknown & $2(3.0 \%)$ & $1(0.7 \%)$ & \\
Lymph nodes & & & 0.73 \\
$\quad 0$ & $12(18.2 \%)$ & $20(14.4 \%)$ & \\
$\geq 1$ & $50(75.8 \%)$ & $112(80.6 \%)$ & \\
$\quad$ unknown & $4(6.1 \%)$ & $7(5.0 \%)$ & \\
Grade & & & 0.62 \\
1 & $1(1.5 \%)$ & $2(1.4 \%)$ & \\
2 & $17(25.8 \%)$ & $46(33.1 \%)$ & \\
$>2$ & $43(65.2 \%)$ & $85(61.2 \%)$ & \\
$\quad$ Unknown & $5(7.6 \%)$ & $6(4.3 \%)$ & \\
\hline
\end{tabular}

SD, standard deviation stratified by tumor size due to non proportional hazard, resulted in an only slightly deviating adjusted HR of 2.64 (95\% CI 1.22 to $5.71 ; P=0.014)$.

Interestingly, in the subgroup of patients subsequently treated with tamoxifen the effect of the UGT2B $7^{268 H \text { His }}$ allele to indicate a poor prognosis became even more pronounced (Figure $2 \mathrm{~b}$, Table 3 ) with an adjusted HR of 5.22 (95\% CI 1.67 to $26.04 ; P=0.015$ ). However, in this model the Firth correction was applied as all patients with nodal status 0 were censored [28].

In the patient subgroup not receiving epirubicin, but tamoxifen in monotherapy $(n=305)$, there was no association of invasive disease-free survival with the $U G T 2 B 7^{\text {His } 268 T y r}$ genotype $(\log$-rank $P=0.20)$, as well as in any other patient group not receiving epirubicin (Figure 3, Table 3).

\section{Discussion}

Genetic polymorphisms that might be relevant to drug metabolism and elimination have extensively been studied over the last years to explain between-subject variation in drug responses and to better target corresponding treatments [29-32]. Particularly in breast cancer, genetic polymorphisms of proteins involved in drug transport or metabolism have been shown to affect the efficacy of agents such as tamoxifen, taxanes or aromatase inhibitors $[7,33,34]$. A considerable variation in the response to epirubicin-based chemotherapies has been reported as well [35-37].

The formation of epirubicin glucuronide represent the main inactivating pathway for epirubicin and studies in human liver microsomes expressing a multitude of UGT isoenzymes, revealed that UGT2B7 uniquely converts 


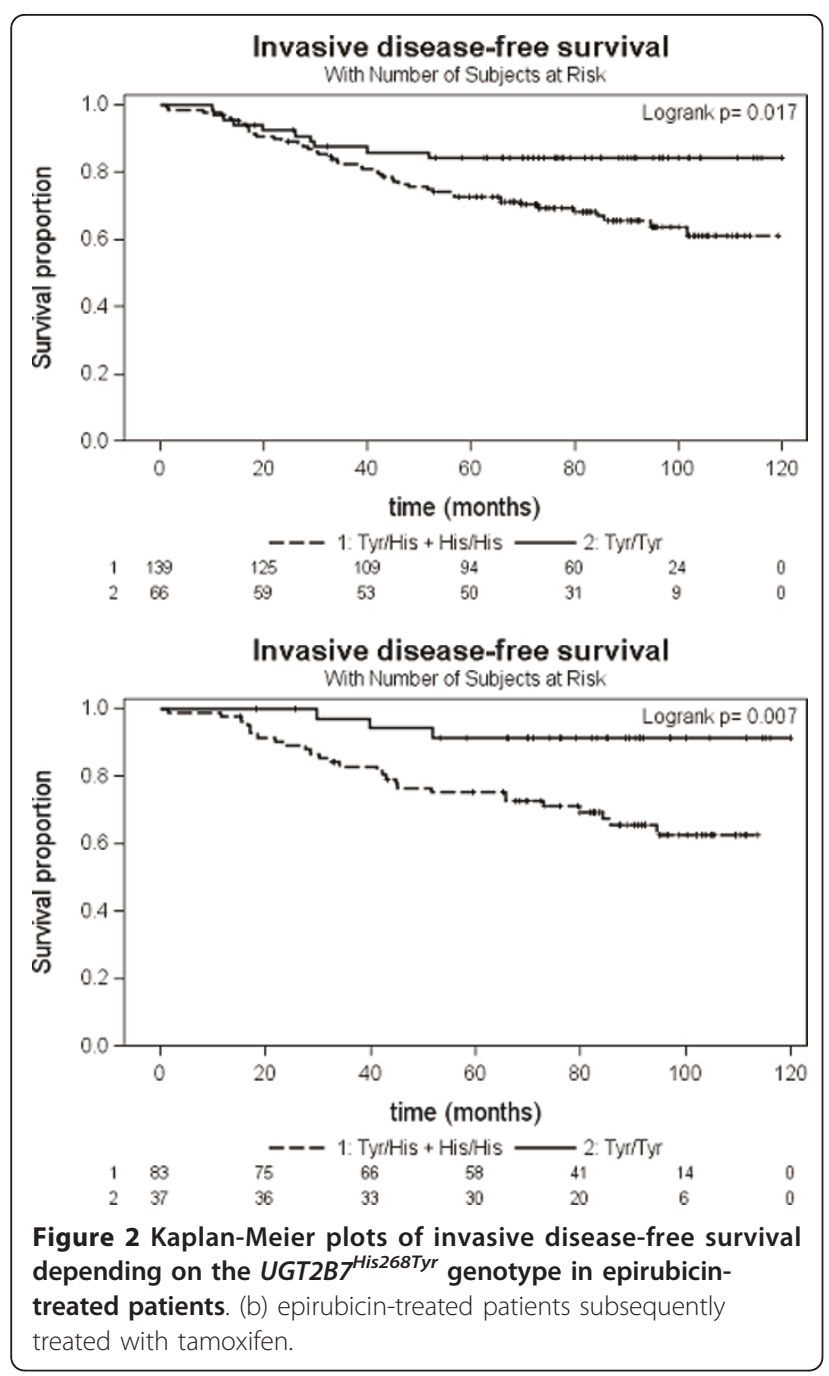

epirubicin to its glucuronide [6]. To the best of our knowledge, this is the first study providing evidence that genetic $U G T 2 B 7$ variation contributes to these clinical observations. In our analysis, epirubicin-treated women with the UGT2B $7^{268 T y r / T y r}$ genotype showed a

Table 3 Invasive disease-free survival according to UGT2B $7^{\text {His268Tyr }}$ genotype and treatment

\begin{tabular}{lcc}
\hline & \multicolumn{2}{c}{ Hazard ratio $(\mathbf{9 5 \%} \mathbf{C l})$} \\
\hline Adjuvant chemotherapy & Crude & Adjusted \\
Epirubicin & $2.24(1.13$ to 4.44$)$ & $2.64(1.22$ to 5.71$)$ \\
& $P=0.021$ & $P=0.014$ \\
Epirubicin/tamoxifen & $4.43(1.34$ to 14.6$)$ & $5.22(1.67-26.04)$ \\
No epirubicin & $P=0.015$ & $P=0.015)$ \\
None & $0.80(0.43$ to 1.49$)$ & $0.78(0.40$ to 1.50$)$ \\
& $P=0.48$ & $P=0.45$ \\
& $0.80(0.47$ to 1.34$)$ & $0.87(0.49$ to 1.55$)$ \\
& $P=0.39$ & $P=0.64$ \\
\hline
\end{tabular}

$\mathrm{Cl}$, confidence interval.

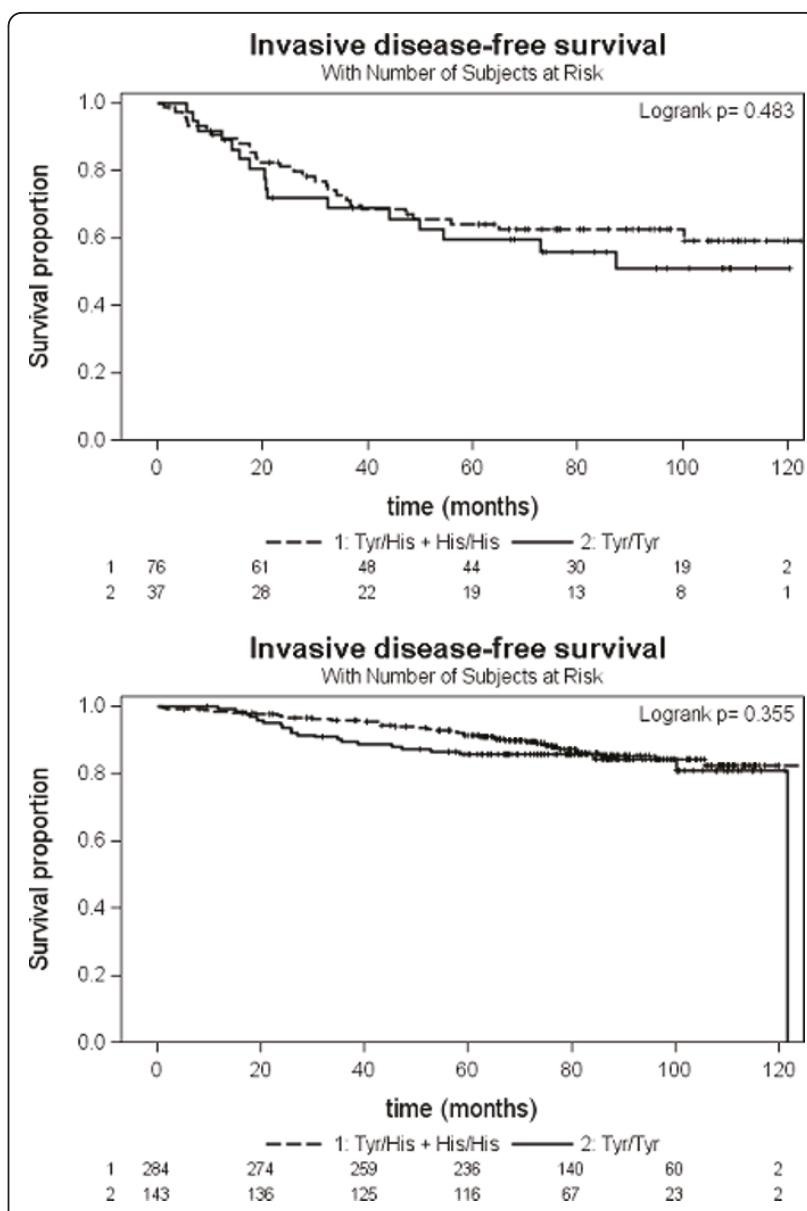

Figure 3 Kaplan-Meier plots of invasive disease-free survival depending on the UGT2B $7^{\text {His268Tyr }}$ genotype in control patients. (a) Patients receiving a combination chemotherapy not containing epirubicin or (b) no adjuvant chemotherapy at all.

significantly better invasive disease-free survival as compared to carriers of at least one UGT2B $7^{268 H i s}$ allele. As the use of epirubicin is quite common and the difference in the average invasive disease-free survival times between both variant carriers amounted to about one year, we think this finding might be of broad interest and high relevance in cancer therapy, although it still needs to be confirmed.

A lower glucuronidation capacity of the UGT2B7 $268 \mathrm{Tyr}$ isoform may delay elimination and cause higher exposure to epirubicin and its active metabolites. This may eventually result in the observed longer invasive diseasefree survival of carriers of the UGT2B $27^{268 T y r / T y r}$ genotype. This is in line with biochemical studies revealing a decreased activity of the UGT2B $7^{268 T y r}$ isoforms assessing other UGT2B7 substrates [8-12]. However, those were contradicted by others [13-18] and by two in vitro studies showing no impact of the UGT2B $7^{H i s 268 T y r}$ genotype on the epirubicin glucuronide formation $[6,19]$. 
One of these studies utilized two lines of HK293 cells expressing the two isoforms generated via site-directed mutagenesis [6]. This methodology implies the disadvantage that the variant leading to an amino acid exchange is solely studied, whereas potentially linked variants remain unconsidered $[6,16]$. This seems to be important, since the UGT2B $7^{\text {His268Tyr }}$ variant appears in frequent haplotypes with other variants, especially promoter variants $(-1306 \mathrm{G}>\mathrm{A},-1299 \mathrm{C}>\mathrm{T},-1112 \mathrm{C}>\mathrm{T}$, $-900 \mathrm{~A}>\mathrm{G},-327 \mathrm{G}>\mathrm{A}$ and $-161 \mathrm{C}>\mathrm{T}$ ) which seem to influence the expression of the two UGT2B7 $7^{\text {His268Tyr }}$ isoforms [13,19-22]. The variant alleles of those promoter variants were associated with a two-fold decreased promoter activity and are perfectly linked with the $U G T 2 B 7^{268 T y r}$ allele [22]. Djebli et al. genotyped the $-900 \mathrm{~A}>\mathrm{G}$ promoter variant beside UGT2B ${ }^{\text {His } 268 T y r}$ and they reported that all individuals carrying the -900GG genotype carried also two variant $U G T 2 B 7^{268 T y r}$ alleles and those who were heterozygote for the promoter variant were as well heterozygote for UGT2B $7^{\text {His } 268-}$ ${ }^{T y r}$ [21]. Using the tagging algorithm implemented in Haploview and the genotype frequencies for the HapMap CEU samples we observed that UGT2B $7^{\text {His } 268 T y r}$ and the linked promoter variants captured $83 \%$ of all genotyped markers (applying a $\mathrm{r}^{2}$ cut-off of 0.8 , minor allele frequency $>0.05$, and using NM_001074 +/- 10 kb) $[38,39]$. The UGT2B $7^{\text {His } 268 T y r}$ variant is further linked to the rather rare promoter variant $-138 \mathrm{G}>\mathrm{A}$ (less than $2 \%$ in Caucasians) which was associated with a seven-fold decreased promoter activity and it cannot be excluded if this variant contributes to our observations [22]. The presently available in vitro studies cannot finally clarify, if those promoter variants may modulate up- or downregulation of the enzyme, especially under the conditions of adjuvant or neoadjuvant chemotherapy. Therefore, it remains unclear if our observations can be mainly attributed to the UGT2B $7^{\text {His268Tyr }}$ variant or to the expressional regulation caused by linked promoter variants. However, in human liver microsomes, genotyped for $U G T 2 B 7^{\text {His } 268 T y r}$, no difference related to this polymorphism in epirubicin glucuronide formation was observed [19], but it is conceivable that there is an up- or downregulation of UGT2B7 caused by anti-cancer drug therapy which may differ inter-individually depending on genetic variants. Whether or not this does play a relevant role in epirubicin treatment cannot finally be clarified by our study but may be an interesting topic for further research. Sawyer et al. also observed differences in morphine glucuronidation studying the linked UGT2B7 -161 C>T variant in pain patients, but failed to confirm their finding in genotyped microsomes [18]. This may indicate differences between the in vitro and the in vivo impact of the variant or the associated UGT2B7 haplotypes.
A few studies have investigated the impact of the UGT2B $7^{268 T y r}$ variant on the in vivo metabolism of other drugs. For mycophenolic acid (MPA), a lower glucuronidation activity and MPA-acyl-glucuronide formation rate through the $U G T 2 B 7^{268 T y r}$ variant was shown $[21,40]$, which resulted in fewer gastrointestinal sideeffects among MPA treated patients [41]. However, in contrast to MPA-acyl-glucuronide [41,42], the glucuronide of epirubicin are not known to contribute considerably to the side effects of the parental drug. Moreover, changes in drug tolerability may affect efficacy outcomes only if those result in changes in treatment adherence. Actually, we have neither data on epirubicin dose modifications and premature discontinuations nor on the incidence of adverse drug reactions. Additionally, an association of the linked UGT2B7 -161 C>T variant with pharmacokinetics of lamotrigine in epileptic patients has been recently reported [43]. By contrast, no effect was observed either on pharmacokinetics of efavirenz or zidovudine in human immunodeficiency virus infected patients $[44,45]$, or on the treatment response to various opioids [46-48]. Given that our study was a retrospective analysis, we unfortunately were not able to determine plasma levels of drug compounds or metabolites. A possible influencing factor might be the younger age among $U G T 2 B 7^{268 T y r / T y r}$ carriers in the epirubicin treated patients group, but although age is a relevant covariate for survival, the relatively small difference in mean age between the different UGT2B7 genotypes is very unlikely to explain a major part of the relatively strong UGT2B7 effects on survival after epirubicin treatment. In addition, we observed no difference in patient age comparing the UGT2B7 genotype groups within the other patient subgroups and no association between age at diagnosis and outcome in the multivariate analysis. Besides, a link to breast cancer risk has also been discussed for the UGT2B $7^{\text {His268Tyr }}$ polymorphism, but no clear evidence has been reported and it is very unlikely that this is a contributing factor to our observations $[49,50]$.

In addition, the association of the $U G T 2 B 7^{268 T y r}$ variant with invasive disease-free survival was even more pronounced in the subgroup of epirubicin-treated women who subsequently received tamoxifen (Figure 2b). Actually, in vitro data suggested reduced glucuronidation rates of the active metabolites 4-hydroxy tamoxifen and endoxifen through the UGT2B $7^{268 \mathrm{Ty}}$ isoform [9], but in contrast to epirubicin, sulfotransferases also play a quantitatively important role [51]. Accordingly, no difference in steady state plasma concentrations of tamoxifen metabolites was observed in 240 breast cancer patients receiving $20 \mathrm{mg}$ tamoxifen daily [52]. In the present study, the sequential treatment with two UGT2B7 substrates resulted in a considerable effect of 
the $U G T 2 B 7^{H i s 268 T y r}$ variant, whereas there was no difference in invasive disease-free survival among patients not treated with epirubicin, including the subgroup of women treated with tamoxifen alone. The more pronounced effect of the $U G T 2 B 7^{\text {His268Tyr }}$ polymorphism in patients treated with both epirubicin and tamoxifen remains currently unexplained and is limited by the rather small sample size of this patient subgroup.

\section{Conclusions}

Breast cancer patients carrying the $U G T 2 B 7^{268 T y r / T y r}$ genotype may benefit most from adjuvant epirubicinbased chemotherapy. Prospective studies with pharmacokinetic measurements and fixed treatment regimens are warranted.

\begin{abstract}
Abbreviations
CA15-3: cancer antigen 15-3; CEA: carcinoembryonic antigen; Cl: confidence interval; HK293: human kidney 293 cell line; HR: hazard ratio; MPA: mycophenolic acid; PCR: polymerase chain reaction; PGt: pharmacogenetic; SD: standard deviation; TIGER: Austrian tumor of breast tissue: incidence, genetics, and environmental risk factors study; UDP: uridine diphosphate; UGT: UDP-glucuronosyltransferase.
\end{abstract}

\section{Acknowledgements}

SP is a fellow of the International Graduate School in Molecular Medicine, Ulm, Germany.

\section{Author details}

${ }^{1}$ Institute of Pharmacology of Natural Products and Clinical Pharmacology, University UIm, Helmholtzstrasse 20, UIm, 89081, Germany. Institute of Medical and Laboratory Diagnostics, Elisabethinen Hospital Linz, Fadingerstrasse 1, Linz, 4020, Austria. ${ }^{3}$ Department of Nephrology and Dialysis, Medical University Vienna, Währingergürtel 18-20, Vienna, 1090, Austria. ${ }^{4}$ Clinical Institute of Medical and Laboratory Diagnostics, Medical University Graz, Auenbruggerplatz 15, Graz, 8036, Austria. ${ }^{5}$ Department of Internal Medicine, Hospital of Fürstenfeld, Krankenhausgasse 1, Fürstenfeld, 8280, Austria. ${ }^{6}$ Department of Clinical Pharmacology, University Göttingen, Robert-Koch-Strasse 40, Göttingen, 37075, Germany. ${ }^{7}$ Christian Doppler Clinic, Private Paracelsus Medical University Salzburg, Ignaz Harrerstrasse 79, Salzburg, 5020, Austria

\section{Authors' contributions}

JCS, WR and EHB conceived the idea for the present analysis and designed the study. WR provided the study material. SP, JCS, AHW, UL, WR, PK and EHB collected the data. SP, JCS, AK, JB, AHW, UL, WR, PK and EHB analyzed and interpreted the data. SP, JCS and EHB prepared the manuscript. All authors revised the manuscript and gave their final approval.

\section{Competing interests}

The authors declare that they have no competing interests.

Received: 25 February 2011 Revised: 15 April 2011

Accepted: 9 June 2011 Published: 9 June 2011

\section{References}

1. Miyoshi $Y$, Kurosumi M, Kurebayashi J, Matsuura N, Takahashi M, Tokunaga E, Egawa C, Masuda N, Kono S, Morimoto K, Kim SJ, Okishiro M, Yanagisawa T, Ueda S, Taguchi T, Tamaki Y, Noguchi S: Predictive factors for anthracycline-based chemotherapy for human breast cancer. Breast Cancer 2010, 17:103-109.

2. Ormrod D, Holm K, Goa K, Spencer C: Epirubicin: a review of its efficacy as adjuvant therapy and in the treatment of metastatic disease in breast cancer. Drugs Aging 1999, 15:389-416.
3. Smith PJ, Soues S: Multilevel therapeutic targeting by topoisomerase inhibitors. Br J Cancer Suppl 1994, 23:S47-51.

4. Simunek T, Sterba M, Popelova O, Adamcova M, Hrdina R, Gers V: Anthracycline-induced cardiotoxicity: overview of studies examining the roles of oxidative stress and free cellular iron. Pharmacol Rep 2009, 61:154-171.

5. Schott B, Robert J: Comparative activity of anthracycline 13dihydrometabolites against rat glioblastoma cells in culture. Biochem Pharmacol 1989, 38:4069-4074.

6. Innocenti F, lyer L, Ramirez J, Green MD, Ratain MJ: Epirubicin glucuronidation is catalyzed by human UDP-glucuronosyltransferase 2B7. Drug Metab Dispos 2001, 29:686-692.

7. Brauch H, Murdter TE, Eichelbaum M, Schwab M: Pharmacogenomics of tamoxifen therapy. Clin Chem 2009, 55:1770-1782.

8. Wiener D, Fang JL, Dossett N, Lazarus P: Correlation between UDPglucuronosyltransferase genotypes and 4-(methylnitrosamino)-1-(3pyridyl)-1-butanone glucuronidation phenotype in human liver microsomes. Cancer Res 2004, 64:1190-1196.

9. Blevins-Primeau AS, Sun D, Chen G, Sharma AK, Gallagher CJ, Amin S, Lazarus P: Functional significance of UDP-glucuronosyltransferase variants in the metabolism of active tamoxifen metabolites. Cancer Res 2009, 69:1892-1900.

10. Barbier O, Turgeon D, Girard C, Green MD, Tephly TR, Hum DW, Belanger A: 3'-azido-3'-deoxythimidine (AZT) is glucuronidated by human UDPglucuronosyltransferase 2B7 (UGT2B7). Drug Metab Dispos 2000, 28:497-502.

11. Gall WE, Zawada G, Mojarrabi B, Tephly TR, Green MD, Coffman BL, Mackenzie PI, Radominska-Pandya A: Differential glucuronidation of bile acids, androgens and estrogens by human UGT1A3 and 2B7. J Steroid Biochem Mol Biol 1999, 70:101-108.

12. Bhasker CR, McKinnon W, Stone A, Lo AC, Kubota T, Ishizaki T, Miners JO: Genetic polymorphism of UDP-glucuronosyltransferase 2B7 (UGT2B7) at amino acid 268: ethnic diversity of alleles and potential clinical significance. Pharmacogenetics 2000, 10:679-685.

13. Court MH, Krishnaswamy S, Hao Q, Duan SX, Patten CJ, Von Moltke LL, Greenblatt DJ: Evaluation of 3'-azido-3'-deoxythymidine, morphine, and codeine as probe substrates for UDP-glucuronosyltransferase 2B7 (UGT2B7) in human liver microsomes: specificity and influence of the UGT2B7*2 polymorphism. Drug Metab Dispos 2003, 31:1125-1133.

14. Peterkin VC, Bauman JN, Goosen TC, Menning L, Man MZ, Paulauskis JD, Williams JA, Myrand SP: Limited influence of UGT1A1*28 and no effect of $\mathrm{UGT}_{2} \mathrm{~B}^{*} 2$ polymorphisms on UGT1A1 or UGT2B7 activities and protein expression in human liver microsomes. Br J Clin Pharmacol 2007, 64:458-468.

15. Bernard O, Tojcic J, Journault K, Perusse L, Guillemette C: Influence of nonsynonymous polymorphisms of UGT1A8 and UGT2B7 metabolizing enzymes on the formation of phenolic and acyl glucuronides of mycophenolic acid. Drug Metab Dispos 2006, 34:1539-1545.

16. Coffman BL, King CD, Rios GR, Tephly TR: The glucuronidation of opioids, other xenobiotics, and androgens by human UGT2B7Y(268) and UGT2B7H(268). Drug Metab Dispos 1998, 26:73-77.

17. Thibaudeau J, Lepine J, Tojcic J, Duguay Y, Pelletier G, Plante M, Brisson J, Tetu B, Jacob S, Perusse L, Belanger A, Guillemette C: Characterization of common UGT1A8, UGT1A9, and UGT2B7 variants with different capacities to inactivate mutagenic 4-hydroxylated metabolites of estradiol and estrone. Cancer Res 2006, 66:125-133.

18. Sawyer MB, Innocenti F, Das S, Cheng C, Ramirez J, Pantle-Fisher FH, Wright C, Badner J, Pei D, Boyett JM, Cook E Jr, Ratain MJ: A pharmacogenetic study of uridine diphosphate-glucuronosyltransferase 2B7 in patients receiving morphine. Clin Pharmacol Ther 2003, 73:566-574.

19. Innocenti F, Liu W, Fackenthal D, Ramirez J, Chen P, Ye X, Wu X, Zhang W, Mirkov S, Das S, Cook E Jr, Ratain MJ: Single nucleotide polymorphism discovery and functional assessment of variation in the UDPglucuronosyltransferase 2B7 gene. Pharmacogenet Genomics 2008, 18:683-697.

20. Holthe M, Rakvag TN, Klepstad P, Idle JR, Kaasa S, Krokan HE, Skorpen F: Sequence variations in the UDP-glucuronosyltransferase 2B7 (UGT2B7) gene: identification of 10 novel single nucleotide polymorphisms (SNPs) and analysis of their relevance to morphine glucuronidation in cancer patients. Pharmacogenomics J 2003, 3:17-26. 
21. Djebli N, Picard N, Rerolle JP, Le Meur Y, Marquet P: Influence of the UGT2B7 promoter region and exon 2 polymorphisms and comedications on Acyl-MPAG production in vitro and in adult renal transplant patients. Pharmacogenet Genomics 2007, 17:321-330.

22. Duguay $Y$, Baar C, Skorpen F, Guillemette C: A novel functional polymorphism in the uridine diphosphate-glucuronosyltransferase 2B7 promoter with significant impact on promoter activity. Clin Pharmacol Ther 2004, 75:223-233.

23. Tojcic J, Benoit-Biancamano MO, Court MH, Straka RJ, Caron $P$, Guillemette C: In vitro glucuronidation of fenofibric acid by human UDPglucuronosyltransferases and liver microsomes. Drug Metab Dispos 2009, 37:2236-2243.

24. Langsenlehner U, Wolf G, Langsenlehner T, Gerger A, Hofmann G, Clar H, Wascher TC, Paulweber B, Samonigg H, Krippl P, Renner W: Genetic polymorphisms in the vascular endothelial growth factor gene and breast cancer risk. The Austrian "tumor of breast tissue: incidence, genetics, and environmental risk factors" study. Breast Cancer Res Treat 2008, 109:297-304

25. Krippl P, Langsenlehner U, Samonigg H, Renner W, Koppel H: Vascular endothelial growth factor in predicting outcome in breast cancer. Clin Cancer Res 2004, 10:8752-8753.

26. Stingl JC, Parmar S, Huber-Wechselberger A, Kainz A, Renner W, Seeringer A, Brockmoller J, Langsenlehner U, Krippl P, Haschke-Becher E: Impact of CYP2D6*4 genotype on progression free survival in tamoxifen breast cancer treatment. Curr Med Res Opin 2010, 26:2535-2542.

27. Hudis CA, Barlow WE, Costantino JP, Gray RJ, Pritchard KI, Chapman JA, Sparano JA, Hunsberger S, Enos RA, Gelber RD, Zujewski JA: Proposal for standardized definitions for efficacy end points in adjuvant breast cancer trials: the STEEP system. J Clin Oncol 2007, 25:2127-2132.

28. Heinze $G$, Schemper $M$ : A solution to the problem of monotone likelihood in Cox regression. Biometrics 2001, 57:114-119.

29. Daly AK: Pharmacogenetics and human genetic polymorphisms. Biochem J 2010, 429:435-449.

30. Coate L, Cuffe S, Horgan A, Hung RJ, Christiani D, Liu G: Germline Genetic Variation, Cancer Outcome, and Pharmacogenetics. J Clin Oncol 2010, 28:4029-4037.

31. Innocenti F, Ratain MJ: Pharmacogenetics of irinotecan: clinical perspectives on the utility of genotyping. Pharmacogenomics 2006, 7:1211-1221

32. Zhang X, Diasio RB: Regulation of human dihydropyrimidine dehydrogenase: implications in the pharmacogenetics of 5-FU-based chemotherapy. Pharmacogenomics 2007, 8:257-265.

33. Hoskins JM, Carey LA, McLeod HL: CYP2D6 and tamoxifen: DNA matters in breast cancer. Nat Rev Cancer 2009, 9:576-586.

34. Longo R, D'Andrea M, Sarmiento R, Gasparini G: Pharmacogenetics in breast cancer: focus on hormone therapy, taxanes, trastuzumab and bevacizumab. Expert Opin Investig Drugs 2010, 19(Suppl 1):S41-50.

35. Jakobsen P, Steiness E, Bastholt L, Dalmark M, Lorenzen A, Petersen D, Gjedde SB, Sandberg E, Rose C, Nielsen OS, Mouridsen HT, Jakobsen A: Multiple-dose pharmacokinetics of epirubicin at four different dose levels: studies in patients with metastatic breast cancer. Cancer Chemother Pharmacol 1991, 28:63-68.

36. Dobbs NA, Twelves $\mathrm{CJ}$ : What is the effect of adjusting epirubicin doses for body surface area? Br J Cancer 1998, 78:662-666.

37. Robert J, David M, Granger C: Metabolism of epirubicin to glucuronides: relationship to the pharmacodynamics of the drug. Cancer Chemother Pharmacol 1990, 27:147-150.

38. Barrett JC, Fry B, Maller J, Daly MJ: Haploview: analysis and visualization of LD and haplotype maps. Bioinformatics 2005, 21:263-265.

39. International Hapmap Project. [http://hapmap.ncbi.nlm.nih.gov].

40. Baldelli S, Merlini S, Perico N, Nicastri A, Cortinovis M, Gotti E, Remuzzi G, Cattaneo D: C-440T/T-331C polymorphisms in the UGT1A9 gene affect the pharmacokinetics of mycophenolic acid in kidney transplantation. Pharmacogenomics 2007, 8:1127-1141.

41. Yang JW, Lee PH, Hutchinson IV, Pravica V, Shah T, Min Dl: Genetic polymorphisms of MRP2 and UGT2B7 and gastrointestinal symptoms in renal transplant recipients taking mycophenolic acid. Ther Drug Monit 2009, 31:542-548.

42. Shipkova M, Armstrong W, Oellerich M, Wieland E: Acyl glucuronide drug metabolites: toxicological and analytical implications. Ther Drug Monit $2003,25: 1-16$
43. Blanca Sanchez M, Herranz $J$, Leno C, Arteaga R, Oterino A, Valdizan EM, Nicolas JM, Adin J, Shushtarian M, Armijo JA: UGT2B7_-161C > T polymorphism is associated with lamotrigine concentration-to-dose ratio in a multivariate study. Ther Drug Monit 2010, 32:177-184.

44. Kwara A, Lartey M, Boamah I, Rezk NL, Oliver-Commey J, Kenu E, Kashuba AD, Court MH: Interindividual variability in pharmacokinetics of generic nucleoside reverse transcriptase inhibitors in TB/HIV-coinfected Ghanaian patients: UGT2B7* $1 \mathrm{C}$ is associated with faster zidovudine clearance and glucuronidation. J Clin Pharmacol 2009, 49:1079-1090.

45. Elens L, Vandercam B, Yombi JC, Lison D, Wallemacq P, Haufroid V: Influence of host genetic factors on efavirenz plasma and intracellular pharmacokinetics in HIV-1-infected patients. Pharmacogenomics 2010, 11:1223-1234.

46. Crettol S, Deglon JJ, Besson J, Croquette-Krokar M, Hammig R, Gothuey I, Monnat M, Eap CB: ABCB1 and cytochrome P450 genotypes and phenotypes: influence on methadone plasma levels and response to treatment. Clin Pharmacol Ther 2006, 80:668-681.

47. Coulbault L, Beaussier M, Verstuyft C, Weickmans H, Dubert L, Tregouet D, Descot C, Parc Y, Lienhart A, Jaillon P, Becquemont L: Environmental and genetic factors associated with morphine response in the postoperative period. Clin Pharmacol Ther 2006, 79:316-324.

48. Ross JR, Rutter D, Welsh K, Joel SP, Goller K, Wells AU, Du Bois R, Riley J: Clinical response to morphine in cancer patients and genetic variation in candidate genes. Pharmacogenomics J 2005, 5:324-336.

49. Sparks R, Ulrich CM, Bigler J, Tworoger SS, Yasui Y, Rajan KB, Porter P, Stanczyk FZ, Ballard-Barbash R, Yuan X, Lin MG, McVarish L, Aiello EJ, McTiernan A: UDP-glucuronosyltransferase and sulfotransferase polymorphisms, sex hormone concentrations, and tumor receptor status in breast cancer patients. Breast Cancer Res 2004, 6:R488-498.

50. Chang-Claude J, Beckmann L, Corson C, Hein R, Kropp SPM, Dünnebier T, Hamann U, Brors B, Eils R, Zapatka M, Brauch H, Justenhoven C, FleschJanys D, Braendle W, Brüning T, Pesch B, Spickenheuer A, Krankenhaus J, Ko YD, Baisch C, Dahmen N, Brauch H, Chang-Claude J, Corson C, Dünnebier T, Hein R, Justenhoven C, Parthimos M, Zapatka M: Genetic polymorphisms in phase I and phase II enzymes and breast cancer risk associated with menopausal hormone therapy in postmenopausal women. Breast Cancer Res Treat 2010, 119:463-474.

51. Nishiyama T, Ogura K, Nakano H, Ohnuma T, Kaku T, Hiratsuka A, Muro K, Watabe $\mathrm{T}$ : Reverse geometrical selectivity in glucuronidation and sulfation of cis- and trans-4-hydroxytamoxifens by human liver UDPglucuronosyltransferases and sulfotransferases. Biochem Pharmacol 2002, 63:1817-1830.

52. Murdter TE, Schroth W, Brauch H, Eichelbaum M, Schwab M: Variability of tamoxifen metabolism in vivo is influenced by genotypes of drug metabolizing enzymes. Basic \& Clinical Pharmacology \& Toxicology 2010 107(suppl 1):abstr 2922, 480.

doi:10.1186/bcr2894

Cite this article as: Parmar et al.: Impact of UGT2B7 His268Tyr polymorphism on the outcome of adjuvant epirubicin treatment in breast cancer. Breast Cancer Research 2011 13:R57.

\section{Submit your next manuscript to BioMed Central and take full advantage of:}

- Convenient online submission

- Thorough peer review

- No space constraints or color figure charges

- Immediate publication on acceptance

- Inclusion in PubMed, CAS, Scopus and Google Scholar

- Research which is freely available for redistribution

Submit your manuscript at www.biomedcentral.com/submit
C Biomed Central 